\title{
Bmi1 gene silencing inhibits the proliferation and invasiveness of human hepatocellular carcinoma cells and increases their sensitivity to 5-fluorouracil
}

\author{
RUI ZHANG, LEI-BO XU, XIU-JING YUE, XIAN-HUAN YU, JIE WANG and CHAO LIU \\ Department of Hepato-Pancreato-Biliary Surgery, Sun Yat-Sen Memorial Hospital, \\ Sun Yat-Sen University, Guangzhou 510120, Guangdong Province, P.R. China
}

Received April 30, 2012; Accepted July 27, 2012

DOI: $10.3892 /$ or.2012.2189

\begin{abstract}
The Bmil gene has been reported to play important roles in cancer initiation and progression. The aim of this study was to investigate the effects of RNA interference (RNAi)mediated silencing of Bmil gene expression on the proliferation and invasiveness of hepatocellular carcinoma (HCC) cells and on the efficacy of chemotherapy in HCC patients. The Bmil gene was silenced by Bmil-siRNA (small interfering RNA) in the human HCC cell lines HepG2 and Bel-7402, and the gene expression levels were assayed by real-time quantitative reverse transcription-polymerase chain reaction (qRT-PCR) and western blotting. The proliferation and migration of Bmilsilenced tumor cells and their sensitivity to 5-FU treatment were determined by Cell Counting Kit-8 (CCK-8), transwell assays and 4',6-diamidino-2-phenylindole (DAPI) staining and flow cytometry, respectively. Bmil-siRNA inhibited the Bmil expression at both the mRNA and protein levels in HCC cells. Proliferation and migration of HCC cells treated with Bmil-siRNA was significantly lower compared to that of the control cells. Moreover, Bmil gene silencing increased the percentage of apoptotic cells treated by 5-FU and decreased the $\mathrm{IC}_{50}$ values of 5-FU to a greater extent. Downregulation of the Bmil gene by RNAi can inhibit the proliferation and invasivesness of HCC cells and increase their sensitivity to 5-FU treatment.
\end{abstract}

\section{Introduction}

Hepatocellular carcinoma (HCC) is one of the most common cancers in the world and has an extremely poor prognosis.

Correspondence to: Dr Chao Liu, Department of HepatoPancreato-Biliary Surgery, Sun Yat-Sen Memorial Hospital, Sun Yat-Sen University, Guangzhou 510120, Guangdong Province, P.R. China

E-mail: mdliuchao@hotmail.com

Key words: hepatocellular carcinoma, Bmil, RNA interference, 5-fluorouracil, drug resistance
Hepatectomy and liver transplantation are the best curative procedures for patients with HCC. However, only $\sim 10-15 \%$ of newly detected cases of HCC can be treated by surgery (1). Adjuvant treatments, including transarterial chemoembolization (TACE), percutaneous ethanol injection (PEI), and radiofrequency ablation (RFA), have been shown to be effective in reducing tumor bulk. Recently, sorafenib was recommended for advanced HCC patients with compensated liver function (2). For the majority of patients presenting with advanced disease, systemic chemotherapy is not the standard treatment option, as HCC has low sensitivity to most chemotherapeutic agents. However, in some cases, it was reported that combination chemotherapy might make some initially unresectable tumors resectable and even induce a complete pathologic response $(3,4)$. 5-Fluorouracil $(5-\mathrm{FU})$ is an important chemotherapeutic agent for HCC; however, after several cycles of 5-FU-based chemotherapy, the tumors may develop drug resistance, and the mechanism of which remains unclear (5).

The oncogene B cell-specific Moloney murine leukemia virus integration site 1 (Bmi1) has been reported to play important roles in stem cell pluripotency, cell proliferation, early embryogenesis, and cancer initiation and progression (6). In addition, the Bmil gene is often highly expressed in HCC, but its significance was not fully clarified (7-9). In this study, we found that downregulation of the Bmil gene by RNA interference (RNAi) could inhibit the proliferation and invasiveness of human HCC cells, and increase their sensitivity to 5-FU treatment in vitro.

\section{Materials and methods}

Cell culture. Two human HCC cell lines HepG2 and Bel-7402 were obtained from the American Type Culture Collection (Manassas, VA, USA) and cultured in RPMI-1640 (Invitrogen Co., Carlsbad, CA, USA) supplemented with $10 \%$ heatinactivated fetal bovine serum (Invitrogen) as recommended by the supplier. All cultures were maintained in humidified atmosphere containing $5 \% \mathrm{CO}_{2}$ at $37^{\circ} \mathrm{C}$.

siRNA transfection. For the RNAi analyses, human Bmi1 small interfering RNA (siRNA) with the nucleotide sequence 5'-CCAAGAUAUUGUAUACAAATT-3' (sense) and 5'-UUU 
Table I. Primers for Bmi1, E-cadherin and reference genes.

\begin{tabular}{lll}
\hline Gene & Primer & \multicolumn{1}{c}{ Sequence } \\
\hline Bmi1 & Forward & 5'-AGCAGCAATGACTGTGATGC-3' \\
& Reverse & 5'-CAGTCTCAGGTATCAACCAG-3' \\
E-cadherin & Forward & 5'-CTGAGAACGAGGCTAACG-3' \\
& Reverse & 5'-GTCCACCATCATCATTCAATAT-3' \\
GAPDH & Forward & 5'-GCACCGTCAAGGCTGAGAAC-3' \\
& Reverse & 5'-TGGTGAAGACGCCAGTGGA-3' \\
\hline
\end{tabular}

GUAUACAAUAUCUUGGTT-3' (antisense), corresponding to part of the Bmil mRNA, and the negative control scrambled siRNA (NC-siRNA; sense, 5'-UUCUCCGAACGUGUCACG UTT-3', antisense, 5'-ACGUGACAGGUUCGGAGAATT-3') were designed and purchased from Shanghai GenePharma Corp. (Shanghai, China). All of the siRNA sequences were subjected to basic local alignment search tool (BLAST) to confirm the absence of homology to any additional known coding sequences in the human genome. Cells were transfected using the Lipofectamine 2000 reagent (Invitrogen) according to the manufacturer's protocol. Briefly, one day prior transfection, HepG2 and Bel-7402 cells (1.5x10 $/$ well) were cultured in 6-well tissue culture plates until they reached $50 \%$ confluence, then the cells were transiently transfected with either Bmil-siRNA or NC-siRNA (100 nM).

Quantitative real-time reverse transcription-polymerase chain reaction ( $q R T-P C R)$. Total RNA was isolated using RNAiso Plus reagent according to the manufacturer's protocol (Takara, Tokyo, Japan). cDNA was synthesized using the PrimeScript RT Reagent (Takara). Portions of double-stranded cDNA were subjected to PCR with a SYBR-Green Premix Ex Taq (Takara). Primer sets used for real-time PCR amplification were shown in Table I. As a control, the levels of glyceraldehyde phosphate dehydrogenase (GAPDH) expression were also analyzed. The amplification protocol comprised incubations at $95^{\circ} \mathrm{C}$ for $30 \mathrm{sec}, 95^{\circ} \mathrm{C}$ for $5 \mathrm{sec}$ and $65^{\circ} \mathrm{C}$ for $20 \mathrm{sec}$. Incorporation of the SYBR-Green dye into PCR products was monitored in real-time with LightCycler real-time PCR detection system (Roche Applied Science, Indianapolis, IN, USA), thereby allowing determination of the threshold cycle $(\mathrm{Ct})$ at which exponential amplification of products begins.

Western blot analysis. The cells (2x10\%/well) were washed twice with ice-cold PBS (phosphate-buffered saline) and lysed on ice in lysis buffer [50 mM Tris ( $\mathrm{pH} 7.4), 150 \mathrm{mM} \mathrm{NaCl}$, $1 \%$ NP-40, $0.1 \%$ SDS], $1 \%$ protease inhibitor phenylmethanesulfonyl fluoride (PMSF; Sigma, St. Lois, MO, USA). Protein concentration was determined by Lowry assay. Whole cell extracts $(50 \mu \mathrm{g})$ were fractionated by $10 \%$ sodium dodecyl sulfate polyacrylamide gel electrophoresis (SDS-PAGE) and transferred onto polyvinylidene difluoride membrane (Millipore Corp., Bedford, MA, USA). Proteins of interest were revealed with specific antibodies as indicated: rabbit antiBmil polyclonal antibody in a final dilution of 1:300 (Santa Cruz Biotechnology, Santa Cruz, CA, USA), rabbit anti-E- cadherin polyclonal antibody in a final dilution of 1:500 (Santa Cruz Biotechnology), rabbit anti-N-cadherin polyclonal antibody in a final dilution of 1:500 (Santa Cruz Biotechnology), rabbit anti-vimentin polyclonal antibody in a final dilution of 1:500 (Santa Cruz Biotechnology), and mouse anti- $\alpha$-tubulin monoclonal antibody in a final dilution of 1:1,000 (Santa Cruz Biotechnology). The membranes were further incubated with goat anti-rabbit secondary antibody in a final dilution of 1:5,000, or goat anti-mouse secondary antibody in a final dilution of 1:10,000 (Santa Cruz Biotechnology). Then the bound were visualized with the enhanced chemiluminescence (ECL) system (Amersham, UK) and exposed to X-ray film (Fuji, Dielsdorf, Switzerland).

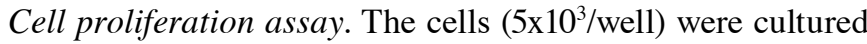
in 96-well tissue culture plates until they reached $50 \%$ confluence, then transfected with a final concentration of $100 \mathrm{nM}$. After transfection (24, 48 and $72 \mathrm{~h}$ ), viability of the cells were determined using the Cell Counting Kit-8 (CCK-8) that was purchased from the Dojindo Molecular Technologies (Gaithersburg, MD, USA). Briefly, $10 \mu \mathrm{l}$ of water soluble formazan dye was added to each well and incubated for $2 \mathrm{~h}$. The absorbance at $450 \mathrm{~nm}$ was measured by an enzyme linked immunosorbent assay (ELISA) plate reader. The absorbance of the negative control (OD) was considered to be $100 \%$.

Cell invasion assay. The invasive activity of tumor cells was estimated using transwells $(6.5 \mathrm{~mm}$ in diameter, polycarbonate membrane, $8 \mu \mathrm{m}$ pore size) coated with extracellular matrix gel obtained from Corning (Corning, NY, USA). Twenty-four hours after transfection, an aliquot of $1 \times 10^{5}$ cells was placed in the upper chamber with $0.1 \mathrm{ml}$ serum-free medium, whereas the lower chamber (24-well plate) was loaded with $0.5 \mathrm{ml}$ of medium containing $10 \%$ fetal bovine serum. After $24 \mathrm{~h}$ of incubation, the cells were fixed with $4 \%$ paraformaldehyde and then counterstained with $0.1 \%$ crystal violet. The cells that had migrated into the lower chamber were observed and counted under a light microscope. Then the number of migratory cells was calculated.

Measurement of cytotoxicity. Twenty-four hours after transfection, the cells were treated with various concentrations (50, 100, 200 and $400 \mu \mathrm{g} / \mathrm{ml}$, respectively) of 5-FU (Sigma) for $48 \mathrm{~h}$. Then the cell viability was determined by CCK- 8 assay. The rate of cell growth inhibition (IR) was calculated according to the following equation: $\mathrm{IR}=[1-\mathrm{A} 570$ (drug) $/ \mathrm{A} 570$ (control)] x 100\%, where A570 (drug) is the absorbance of the cells exposed to 5-FU and A570 (control) is the absorbance of the cells without 5-FU treatment.

DAPI staining. 4,6-Diamidino-2-phenylindole (DAPI, Invitrogen) staining was performed according to the manufacturer's protocol. In brief, cells were fixed with $4 \%$ paraformaldehyde for $30 \mathrm{~min}$ at $25^{\circ} \mathrm{C}$, washed three times with cold PBS, and exposed to $1 \mu \mathrm{g} / \mathrm{ml}$ DAPI solution for $15 \mathrm{~min}$ in the dark at room temperature. Stained cells were observed with a laser scanning microscope (Nikon, Japan).

Flow cytometry. To detect the apoptosis of HCC cells, the cells were doubly stained with Annexin V-FITC (BD Bioscience) 
A
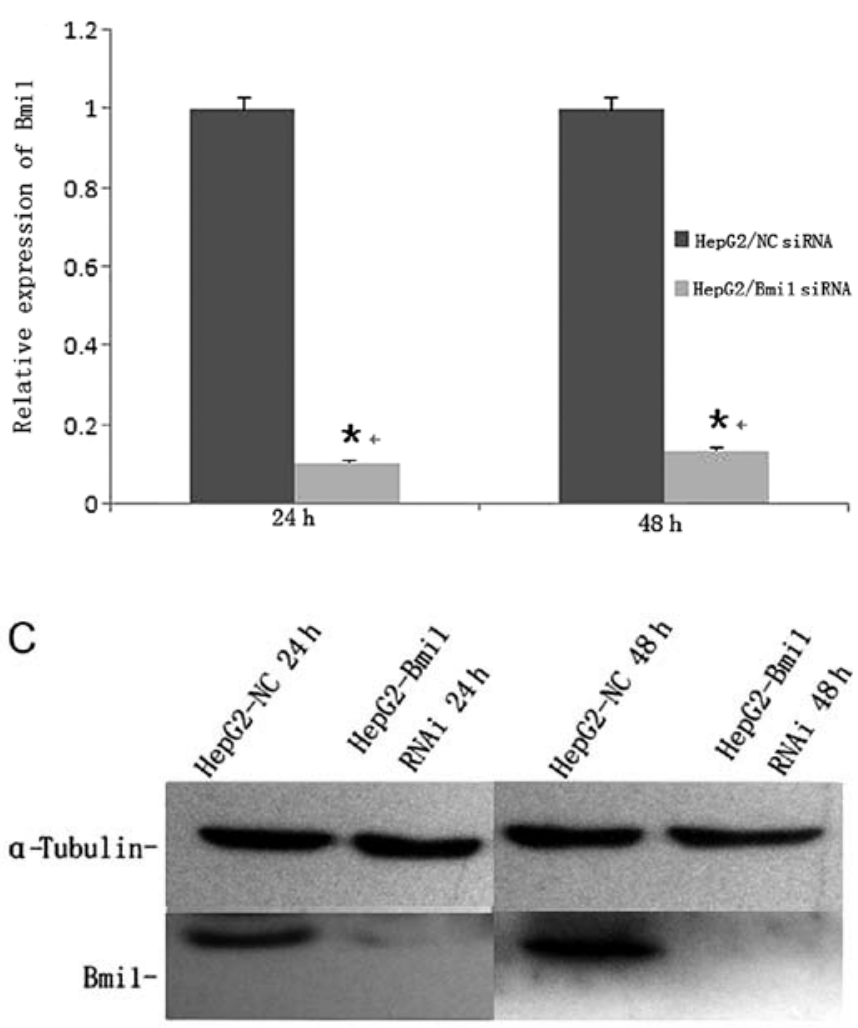

B

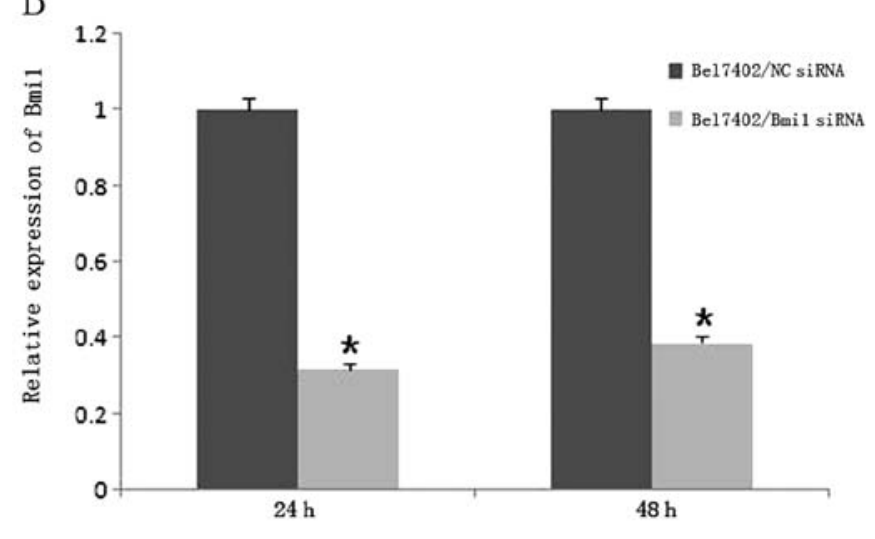

D

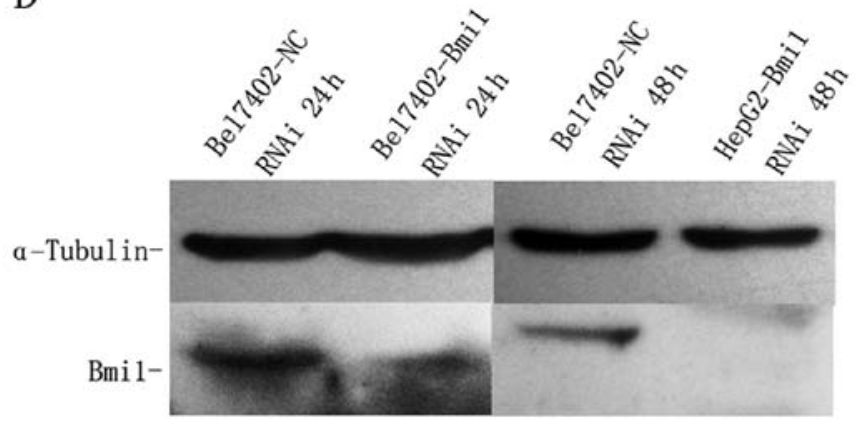

Figure 1. Downregulation of Bmil expressions in HCC cells by RNAi. qRT-PCR analysis showed that the mRNA expression levels of Bmil in HepG2 cells (A) and Bel-7402 cells (B) were significantly downregulated. Similar results appeared in western blot analysis (C and D). * P<0.01.

and propidium iodide followed by flow cytometry (FCM) analysis. Apoptotic ratio was determined on the basis of Annexin $\mathrm{V}^{+} \mathrm{PI}^{+}$and Annexin $\mathrm{V}^{+} \mathrm{PI}^{-}$fractions.

Statistics. All experiments were performed at least in triplicate. Statistical analysis was conducted with the SPSS software package (version 13.0; SPSS Inc., Chicago, IL, USA). All data were presented as the mean \pm standard deviation (SD), and the Student's t-test was used for evaluating the statistical significance. For all tests, a P-value $<0.05$ was considered to be statistically significant and indicated by asterisks in the figures. All P-values given were the results of two-sided tests.

\section{Results}

siRNAs targeting the Bmil gene downregulated Bmil expression in HCC cells. To address the functional importance of the Bmil gene, we employed RNAi to deplete its expressions in HepG2 cells and Bel-7402 cells, both of which were treated with negative control (NC)-siRNA or siRNA targeting the Bmil gene. After 24 and 48 h, the cells were examined by real-time quantitative reverse transcription-polymerase chain reaction (qRT-PCR) and western blot analysis. The qRT-PCR analysis confirmed that the levels of glyceraldehyde3-phosphate dehydrogenase (GAPDH) were unaffected by transfection of Bmil-siRNA or NC-siRNA. As shown in Fig. 1A and B, qRT-PCR showed that Bmil-siRNA dowregu- lated the mRNA expression of Bmil $(\mathrm{P}<0.001)$. Similar results were observed in the western blot analysis (Fig. 1C and D; $\mathrm{P}<0.001)$. In addition, the expression of Bmil in Bmil-siRNA group was significantly lower than that in the control group $(\mathrm{P}<0.001)$. These data indicated that Bmi1-specific siRNA could effectively and obviously suppress the expression of Bmil in HepG2 cells and Bel-7402 cells.

Specific knockdown of Bmil expression by RNAi inhibited the growth of HCC cells in vitro. We then investigated the effect of Bmil-siRNA on the proliferation of HCC cells. To this end, the CCK- 8 assay was performed 24,48 and $72 \mathrm{~h}$ after transfection. Compared to the NC-siRNA, Bmil-siRNA inhibited the growth of HepG2 cells and Bel-7402 cells dramatically in vitro (Fig. $2 \mathrm{~A}$ and $\mathrm{B} ; \mathrm{P}<0.001$ ).

Bmil-siRNA diminished the migration of HepG2 cells in vitro. To examine whether targeted downregulation of Bmil in HepG2 cells affected the migration of tumor cells, in vitro transwell migration assays were performed. The number of tumor cells migrating through the filter in the Bmil-siRNA group was markedly lower than that in the NC-siRNA group (Fig. 3; P<0.001). Thus, Bmi1-siRNA silencing can dramatically diminish the migration of HepG2 cells in vitro.

Knockdown of Bmil can promote the expression of E-cadherin and decrease the expression of vimentin and $N$-cadherin. To further explore the mechanism underlying the repression of 

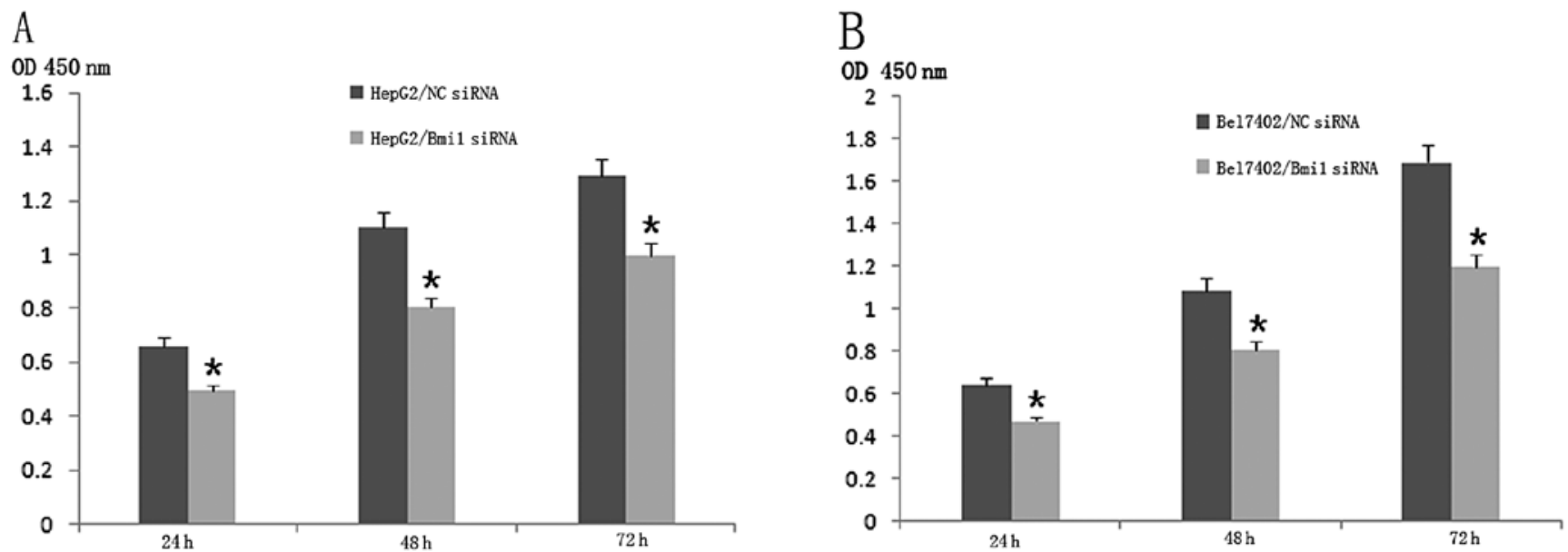

Figure 2. The effect of Bmi1 knockdown on the proliferation of HCC cells 24,48 and $72 \mathrm{~h}$ after transfection. Downregulation of Bmi1 expression by Bmi1siRNA significantly inhibits the growth of HepG2 (A) and Bel-7402 (B) cells. ${ }^{*} \mathrm{P}<0.01$.

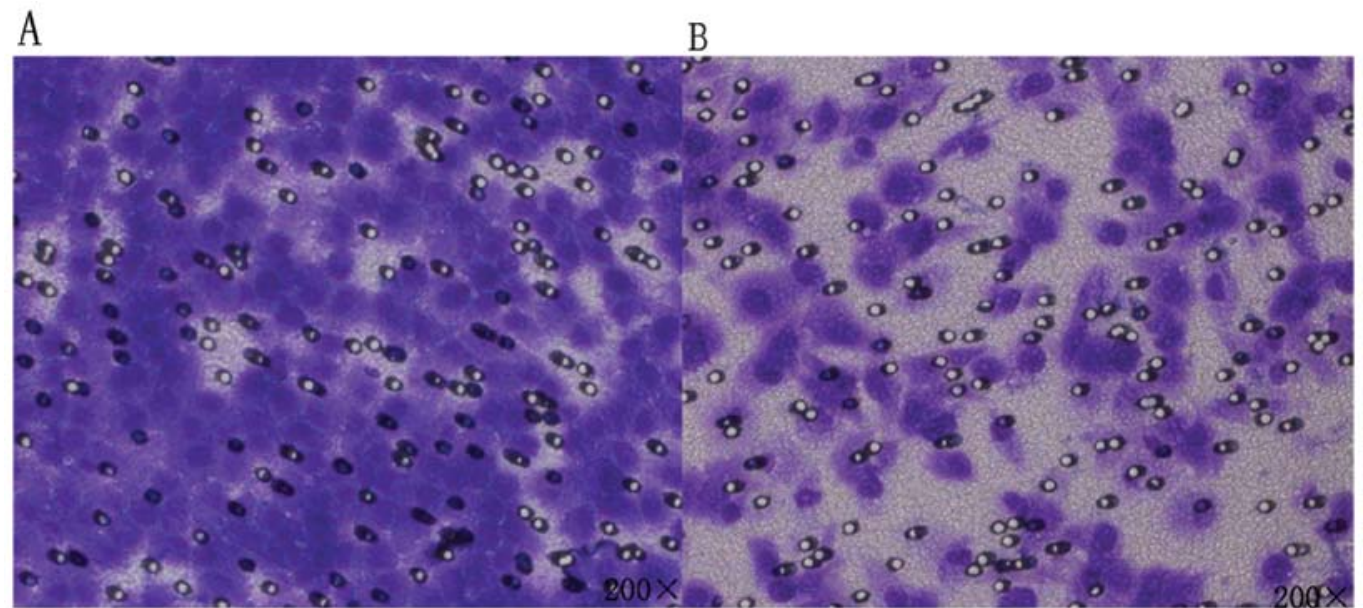

HepG2-NC RNAi $24 \mathrm{~h}$

HepG2-Bmi1 RNAi $24 \mathrm{~h}$

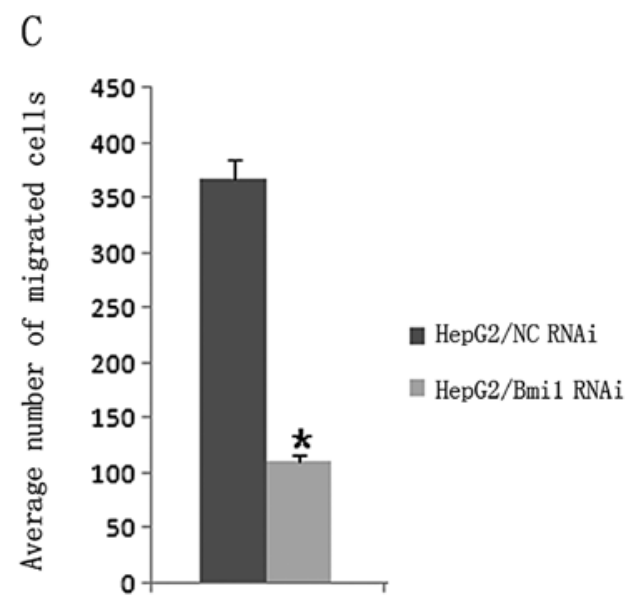

Figure 3. The effect of Bmil knockdown on the invasiveness of HepG2 cells. The number of HepG2 cells that migrating through the filter was markedly lower in Bmil-siRNA group (B) than the NC-siRNA group (A and C). ${ }^{*} \mathrm{P}<0.01$.

HCC cells migration by the silencing of Bmi1, the expression levels of the epithelial-mesenchymal transition (EMT) marker E-cadherin in the HepG2-NC-siRNA and HepG2-Bmi1-siRNA cells were examined. The results showed that knockdown of endogenous Bmil led to substantial enhancement in the levels of E-cadherin (Fig. 4A; $\mathrm{P}<0.001$ ), but decreased the expressions of vimentin and $\mathrm{N}$-cadherin in Bmil knockdown cells (Fig. 4B-D; P<0.001). 
A

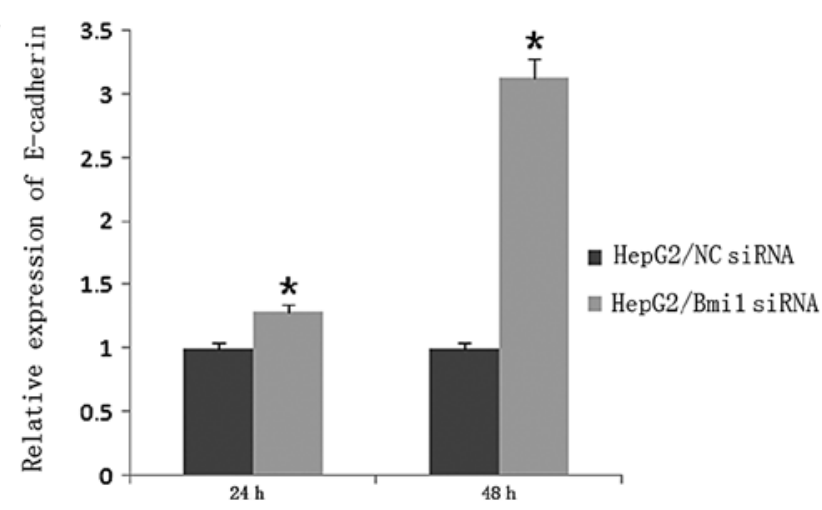

B

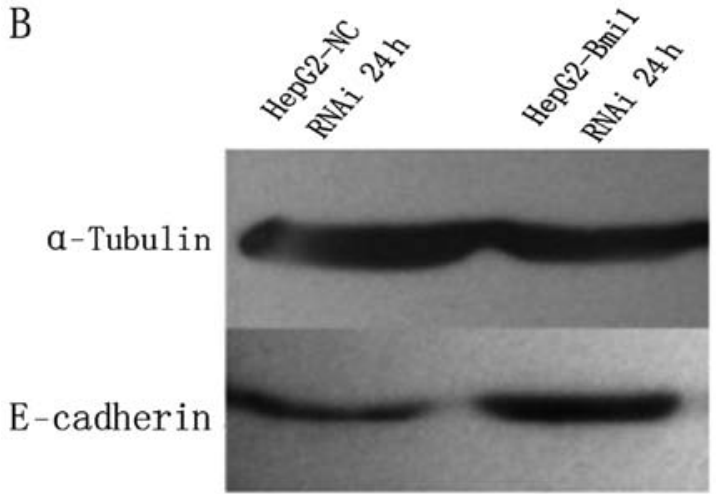

C
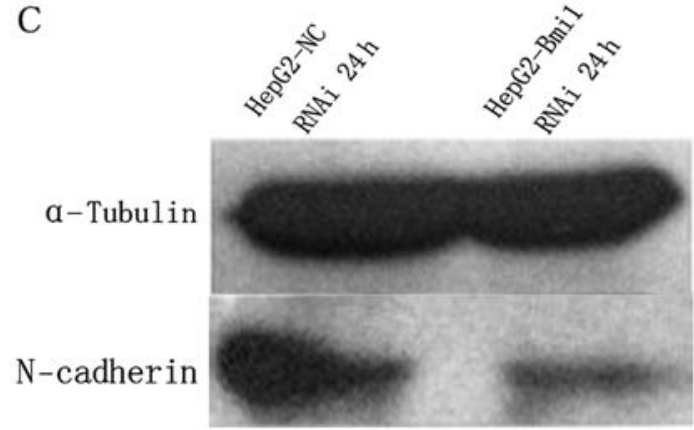

D

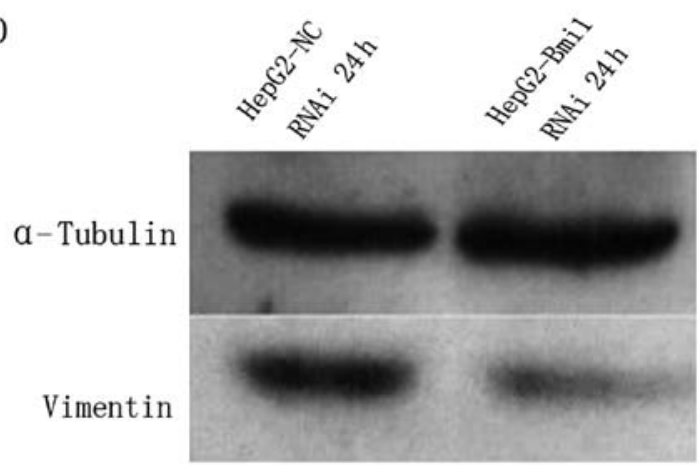

Figure 4. Knockdown of Bmil can promote the expression of E-cadherin and $\mathrm{N}$-cadherin and decrease the expression of vimentin. Bmil knockdown can promote the expressions of E-cadherin at the mRNA level (A) ${ }^{*} \mathrm{P}<0.01$. Western blot analysis showed that the expressions of E-cadherin (B) was increased in Bmil knockdown HepG2 cells, N-cadherin (C) and vimentin (D) were decreased in Bmi1 knockdown HepG2 cells. ${ }^{*} \mathrm{P}<0.01$.

Knockdown of Bmil sensitizes HCC cells to 5-FU-induced apoptosis. To further explore the role of Bmil in HCC, we
A

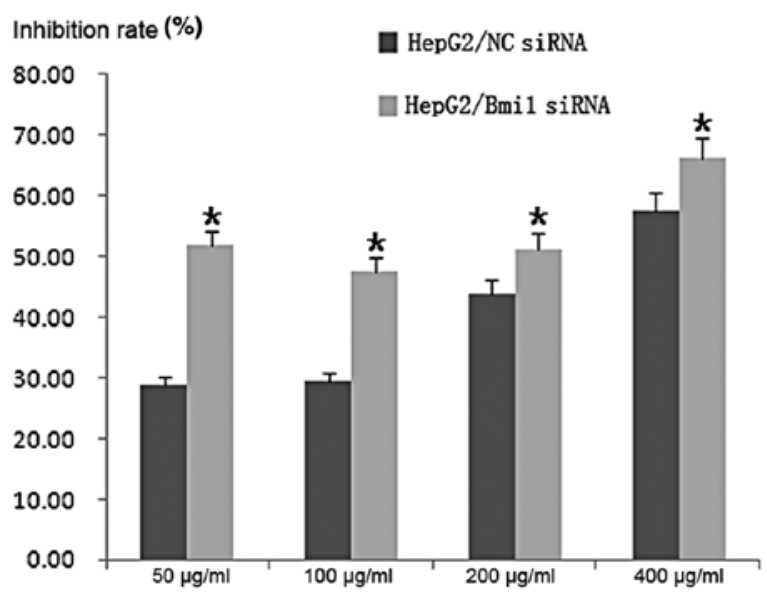

B

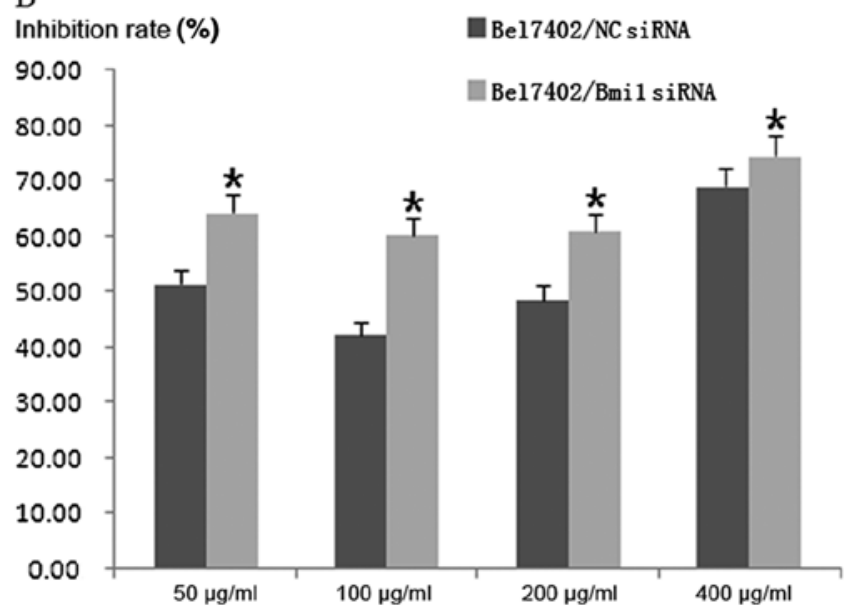

Figure 5. The effect of Bmil knockdown on the chemosensitivity of HCC cells to 5-FU treatment. The inhibition rate of 5-FU in the Bmil-siRNA transfected HCC cells (A, HepG2; B, Bel-7402) were significantly higher that the control. ${ }^{*} \mathrm{P}<0.01$.

tested whether downregulation of Bmil by RNAi sensitizes HCC cells to 5-FU chemotherapy. After transfection and treatment with various concentrations of $5-\mathrm{FU}$, cell viability was determined by the CCK- 8 assay. The results showed that both the Bmi1-siRNA transfected cells (HepG2-Bmil-siRNA and Bel-7402-Bmil-siRNA cells) showed lower cell viabilities than the control (HepG2-NC-siRNA and Bel-7402-NC-siRNA cells; $\mathrm{P}<0.001)$. The $\mathrm{IC}_{50}$ values of 5-FU in the HepG2-NCsiRNA and HepG2-Bmil-siRNA cells were $215.23 \pm 0.89$ and $47.67 \pm 0.70 \mu \mathrm{g} / \mathrm{ml}$, respectively, and the corresponding values for Bel-7402-NC-siRNA and Bel-7402-Bmi1-siRNA cells were $106.63 \pm 0.63$ and $26.21 \pm 0.38 \mu \mathrm{g} / \mathrm{ml}$, respectively (Fig. 5).

In order to confirm these results, the cells were subjected to 4',6-diamidino-2-phenylindole (DAPI) staining. As shown in Fig. 6A and B, both HepG2-Bmi1-siRNA and Bel-7402Bmil-siRNA cells showed lower cell numbers than the control cells. We also examined the apoptotic rate of tumor cells by flow cytometry. The results showed that the apoptotic rates of the HepG2-Bmi1-siRNA and Bel-7402-Bmi1-siRNA cells were much higher than those of the HepG2-NC-siRNA and Bel-7402-NC-siRNA cells, respectively (Fig. 6C; $\mathrm{P}<0.001$ ). 


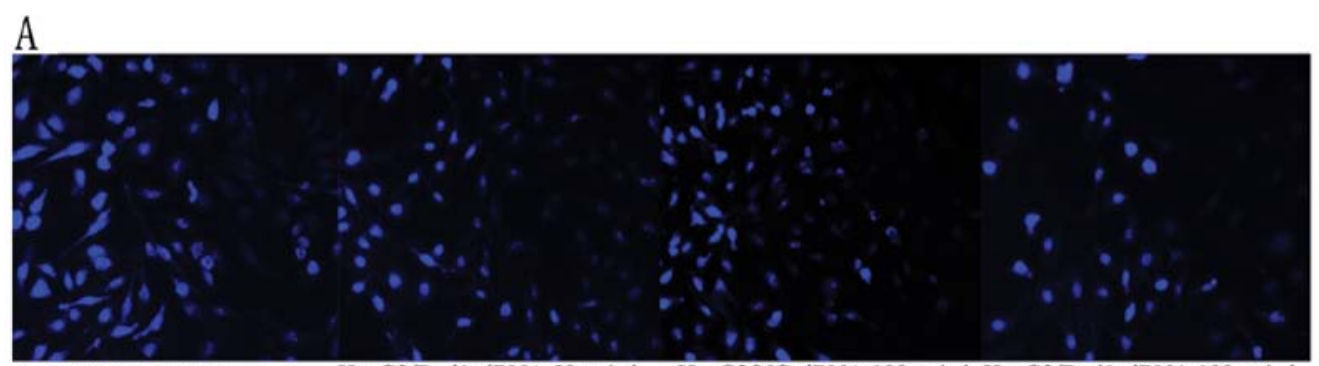

HepG2/NC siRNA $50 \mu \mathrm{g} / \mathrm{ml} \quad$ HepG2/Bmil siRNA $50 \mu \mathrm{g} / \mathrm{ml} \quad$ HepG2/NC siRNA $100 \mu \mathrm{g} / \mathrm{ml}$ HepG2/Bmil siRNA $100 \mu \mathrm{g} / \mathrm{ml}$

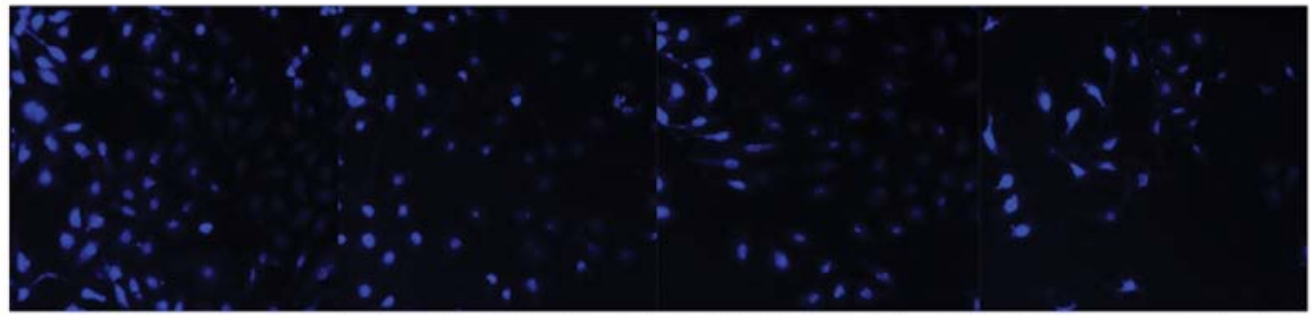

HepG2/NC siRNA $200 \mu \mathrm{g} / \mathrm{ml} \quad \mathrm{HepG} / \mathrm{Bmil}$ siRNA $200 \mu \mathrm{g} / \mathrm{ml} \quad \mathrm{HepG} 2 / \mathrm{NC}$ siRNA $400 \mu \mathrm{g} / \mathrm{ml} \quad \mathrm{HepG} 2 / \mathrm{Bmil}$ siRNA $400 \mu \mathrm{g} / \mathrm{ml}$

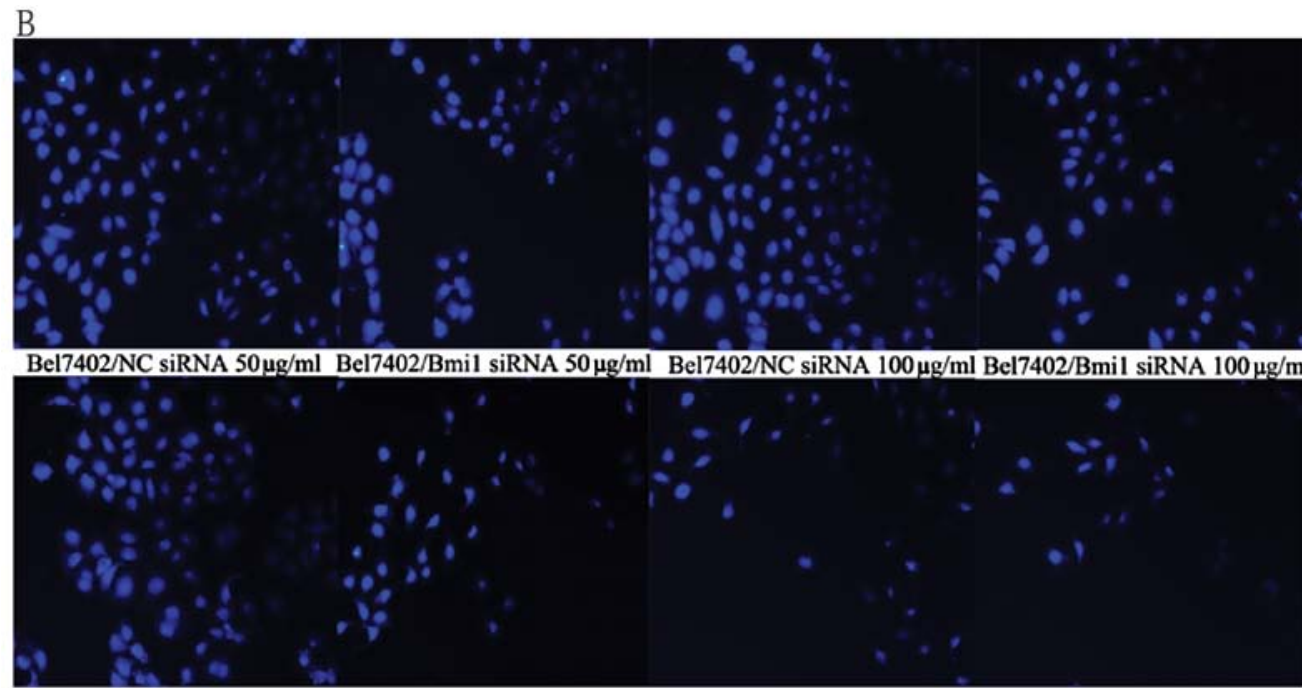

Bel7402/NC siRNA $200 \mu \mathrm{g} / \mathrm{ml}$ Bel7402/Bmil siRNA $200 \mu \mathrm{g} / \mathrm{ml}$ Bel4702/NC siRNA $400 \mu \mathrm{g} / \mathrm{ml}$ Bel $7402 / \mathrm{Bmil}$ siRNA $400 \mu \mathrm{g} / \mathrm{ml}$

$\mathrm{C}$

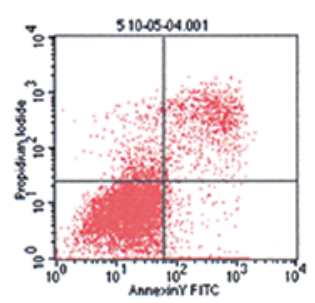

HeoG2/NC siRNA $50 \mu \mathrm{g} / \mathrm{ml}$ apoptotic rate: (16.24 \pm 1.23$) \%$

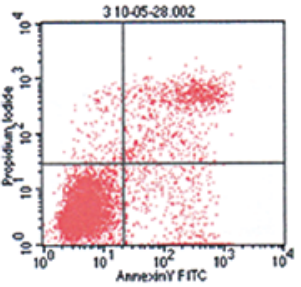

Bel7402/NC siRNA $50 \mu \mathrm{g} / \mathrm{ml}$

apoptotic rate: $(17.56 \pm 2.23) \%$

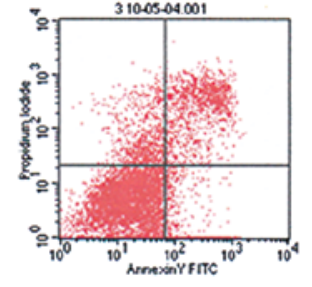

HepG2/Bmil siRNA $50 \mu \mathrm{g} / \mathrm{ml}$ apoptotic rate: $(24.5 \pm 1.78) \%$

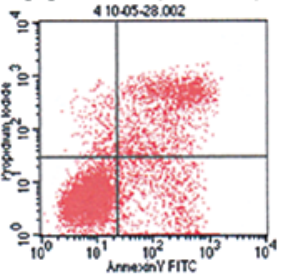

Bel7402/Bmil siRNA $50 \mu \mathrm{g} / \mathrm{ml}$ apoptotic rate: $(33.53 . \pm 1.35) \%$

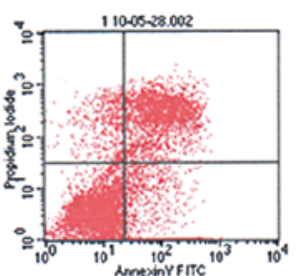

HepG2/NC siRNA $100 \mu \mathrm{g} / \mathrm{ml}$ apoptotic rate: $\mathbf{( 4 2 . 2 5 \pm 3 . 1 7 ) \%}$

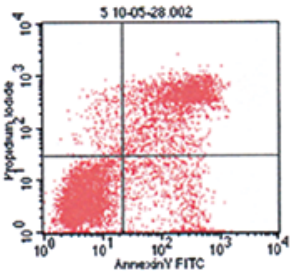

Bel7402/NC siRNA $100 \mu \mathrm{g} / \mathrm{m}$

apoptotic rate: $(41.44 \pm 3.70) \%$

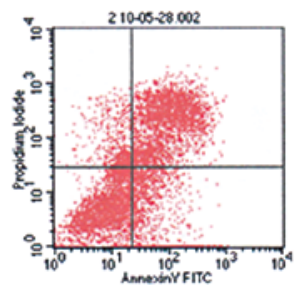

HepG2/Bmil siRNA $100 \mu \mathrm{g} / \mathrm{ml}$ apoptotic rate: $(54.88 \pm 4.42) \%$

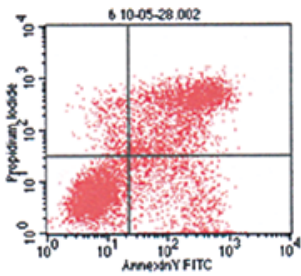

Bel7402/Bmil siRNA $100 \mathrm{ng} / \mathrm{ml}$ apoptotic rate: $(52.53 \% \pm 2.75) \%$

Figure 6. Effect of Bmi1 downregulation on 5-FU-induced apoptosis. Fluorescence images (magnification, $\mathrm{x} 400$ ) of HepG2 cells (A) and Bel-7402 cells (B) stained with DAPI. (C) Flow cytometry analyses of propidium iodide-stained cells to 5-FU and the percentages of apoptotic cells. " $\mathrm{P}<0.01$. 
These results indicated that knockdown of Bmil could sensitize $\mathrm{HCC}$ cells to 5-FU treatment.

\section{Discussion}

A majority of HCC patients who undergo chemotherapy show multidrug resistance (MDR), which is often responsible for therapy failure and poor outcome. However, the precise molecular mechanisms of MDR remain unknown. One explanation for MDR is overexpression of membrane transport proteins such as the P-glycoprotein (P-gp) and the multidrug resistance protein isoform 1 (MRP1), which acts as an efflux pump for anticancer agents (10). In addition, resistance to apoptosis also contributes to chemoresistance (11).

Chemosensitization strategies involving gene therapy, which aim to weaken the pathological activity of MDR-related genes in cancer cells, are currently on the rise. Gene-targeted therapies that enhance cancer cell sensitivity to chemotherapeutic agents have the potential to increase drug efficacy while reducing the toxic effects on untargeted cells (12). This approach needs to be improved and the methods to characterize the chemoresistance profile of cancer need to be standardized. Therefore, the development and improvement of methods to determine the chemoresistance profile have become a crucial objective in developing therapeutic strategies against cancer (13).

RNAi is a relatively new approach and represents a prospective strategy to overcome MDR by selectively silencing the target genes involved in the development of this deleterious phenotype. RNAi technology can be directed against cancer by inhibiting overexpressed oncogenes, blocking cell division by interfering with cyclin $\mathrm{E}$ and related genes, or promoting apoptosis by suppressing antiapoptotic genes (14). Duxbury et al (15) and Yu et al (16) reported that targeting the ribonucleotide reductase M2 subunit and silencing the polo-like kinase 1 gene by RNAi attenuated the cellular invasiveness and gemtacibine chemoresistance of pancreatic adenocarcinoma. Singh et al (17) reported that RNAi-mediated silencing of the expression of nuclear factor erythroid-2-related factor 2 in non-small cell lung cancer inhibited tumor growth and increased the efficacy of chemotherapy. Further, Dong et al (18) reported that in human breast carcinoma cells, tumor-specific RNAi targeting the eIF4E gene suppresses tumor growth, induces apoptosis, and enhances cisplatin cytotoxicity. In contrast, in HCC cells, downregulation of CD147 expression by RNAi-sensitized HCC cells increased the sensitivity of HCC cells to curcumin (19). Chen et al (20) reported that siRNA-mediated downregulation of the expression of $\mathrm{x}$-linked inhibitor of apoptosis reduced cellular viability and increased methotrexate chemosensitivity in the human hepatoma cell line HepG2. However, little is known about the effect of Bmil gene expression on tumor progression and drug resistance in cases of HCC.

Bmil, a member of the polycomb gene ( $\mathrm{PcG}$ ) family, plays important roles in cell cycle regulation, cell immortalization, cell senescence, maintenance of stem cell pluripotency and early embryogenesis (6). In addition, numerous studies have demonstrated that Bmil expression is frequently upregulated in various types of human cancers, including lymphoma (21), lung cancer (22), ovarian cancer (23), nasopharyngeal carcinoma (24,25), breast cancer (26), and HCC (7-9), which indicate that the Bmil gene may be implicated in tumor development and progression. The possible molecular mechanism by which Bmil participates in tumor development and progression is by suppressing p16/retinoblastoma protein $(\mathrm{Rb})$ and/or p19ARF/ MDM2/p53 tumor suppressor pathways. Further, Bmi1 expression is also associated with the protection of tumor cells from apoptosis, which is associated with inhibition of the phosphoinositide-3 kinase (PI3K)/Akt pathway (27).

To examine the role of Bmil expression on the proliferation, invasiveness, and chemotherapeutic response of HCC, the Bmil gene was silenced by Bmil-siRNA in 2 HCC cell lines, HepG2 and Bel-7402. After transfection, the cells were treated with various concentrations of 5-FU. Then, the proliferation, invasiveness, and 5-FU sensitivity of Bmil-silenced tumor cells were detected by CCK-8, transwell assays, DAPI staining, and flow cytometry. The results showed that the proliferation and viability of tumor cells in the Bmil-silenced group were significantly lower than those in the control group. Transwell migration assays showed that downregulation of Bmil expression can significantly diminish the migratory capacity of HCC cells in vitro. We also observed that Bmil gene silencing significantly increased the apoptotic rate of tumor cells treated by $5-\mathrm{FU}$ and significantly decreased the $\mathrm{IC}_{50}$ values of $5-\mathrm{FU}$. These results showed that the knockdown of endogenous Bmil expression contributed to sensitization of $\mathrm{HCC}$ cells to 5-FU, inhibited their proliferation and invasiveness, and increased their apoptotic rates, which suggested that the combination of conventional chemotherapy and Bmil-gene target therapy will be a potential clinical strategy for HCC therapy.

To further investigate the mechanism underlying the inhibition of invasiveness of human HCC cells by RNAi, we examined the expression levels of the EMT markers, E-cadherin, $\mathrm{N}$-cadherin, and vimentin in the HepG2 cells after transfection by qRT-PCR and/or western blot analysis. The results showed that knockdown of endogenous Bmil expression led to significant promotion of E-cadherin expression at both mRNA and protein levels, and the expressions of vimentin and $\mathrm{N}$-cadherin were significantly downregulated. This means that Bmil-RNAi inhibits the invasiveness of human HCC cells, which may be partly mediated through EMT.

In conclusion, we showed the anticancer potential of the combination of 5-FU treatment and Bmil depletion. We found that knockdown of Bmil expression made HCC cells more sensitive to 5-FU treatment and that depletion of Bmil enhanced 5-FU-induced apoptosis. Our study suggests that a combination of 5-FU treatment and Bmil depletion might be a potential novel therapeutic strategy against drug resistance in HCC cells. However, further research is required to better delineate the molecular mechanisms.

\section{Acknowledgements}

This study was supported by the Special Research Foundation of the National Nature Science Foundation of China (81172068).

\section{References}

1. Jemal A, Siegel R, Ward E, et al: Cancer statistics, 2009. CA Cancer J Clin 59: 225-249, 2009. 
2. Morimoto M, Numata K, Kondo M, et al: Higher discontinuation and lower survival rates are likely in elderly Japanese patients with advanced hepatocellular carcinoma receiving sorafenib. Hepatol Res 41: 296-302, 2011.

3. Meric F, Patt YZ, Curley SA, et al: Surgery after downstaging of unresectable hepatic tumors with intra-arterial chemotherapy. Ann Surg Oncol 7: 490-495, 2000.

4. Forner A, Reig ME, de Lope CR, et al: Current strategy for staging and treatment: the BCLC update and future prospects. Semin Liver Dis 30: 61-74, 2010.

5. Farazi PA and DePinho RA: Hepatocellular carcinoma pathogenesis: from genes to environment. Nat Rev Cancer 6: 674-687, 2006.

6. Park IK, Morrison SJ and Clarke MF: Bmi1, stem cells, and senescence regulation. J Clin Invest 113: 175-179, 2004

7. Yonemitsu Y, Imazeki F, Chiba T, et al: Distinct expression of polycomb group proteins EZH2 and BMI1 in hepatocellular carcinoma. Hum Pathol 40: 1304-1311, 2009.

8. Sasaki M, Ikeda H, Itatsu K, et al: The overexpression of polycomb group proteins Bmil and EZH2 is associated with the progression and aggressive biological behavior of hepatocellular carcinoma. Lab Invest 88: 873-882, 2008.

9. Chiba T, Miyagi S, Saraya A, et al: The polycomb gene product BMI1 contributes to the maintenance of tumor-initiating side population cells in hepatocellular carcinoma. Cancer Res 68 : 7742-7749, 2008

10. Munoz M, Henderson M, Haber M, et al: Role of the MRP1/ ABCC1 multidrug transporter protein in cancer. IUBMB Life 59: 752-757, 2007

11. Baguley BC: Multidrug resistance in cancer. Methods Mol Biol 596: 1-14, 2010.

12. Seth P: Vector-mediated cancer gene therapy: an overview. Cancer Biol Ther 4: 512-517, 2005.

13. Baggetto LG, Gambrelle J, Dayan G, et al: Major cytogenetic aberrations and typical multidrug resistance phenotype of uveal melanoma: current views and new therapeutic prospects. Cancer Treat Rev 31: 361-379, 2005.

14. Izquierdo M: Short interfering RNAs as a tool for cancer gene therapy. Cancer Gene Ther 12: 217-227, 2005.

15. Duxbury MS, Matros E, Ito H,Zinner MJ, et al: Systemic siRNAmediated gene silencing: a new approach to targeted therapy of cancer. Ann Surg 240: 667-674, 2004

16. Yu C, Zhang X, Sun G, et al: RNA interference-mediated silencing of the polo-like kinase 1 gene enhances chemosensitivity to gemcitabine in pancreatic adenocarcinoma cells. J Cell Mol Med 12: 2334-2349, 2008.
17. Singh A, Boldin-Adamsky S, Thimmulappa RK, et al: RNAimediated silencing of nuclear factor erythroid-2-related factor 2 gene expression in non-small cell lung cancer inhibits tumor growth and increases efficacy of chemotherapy. Cancer Res 68: 7975-7984, 2008

18. Dong K, Wang R, Wang X, et al: Tumor-specific RNAi targeting eIF4E suppresses tumor growth, induces apoptosis and enhances cisplatin cytotoxicity in human breast carcinoma cells. Breast Cancer Res Treat 113: 443-456, 2009.

19. Jia L, Wang H, Qu S, et al: CD147 regulates vascular endothelial growth factor-A expression, tumorigenicity, and chemosensitivity to curcumin in hepatocellular carcinoma. IUBMB Life 60: 57-63, 2008.

20. Chen J, Xiao XQ, Deng CM, et al: Downregulation of XIAP expression by small interfering RNA inhibits cellular viability and increases chemosensitivity to methotrexate in human hepatoma cell line HepG2. J Chemother 18: 525-531, 2006.

21. Dutton A, Woodman CB, Chukwuma MB, et al: Bmi-1 is induced by the Epstein-Barr virus oncogene LMP1 and regulates the expression of viral target genes in Hodgkin lymphoma cells. Blood 109: 2597-2603, 2007.

22. Breuer RH, Snijders PJ, Sutedja GT, et al: Expression of the p16(INK4a) gene product, methylation of the p16(INK4a) promoter region and expression of the polycomb-group gene BMI-1 in squamous cell lung carcinoma and premalignant endobronchial lesions. Lung Cancer 48: 299-306, 2005.

23. Bhattacharya R, Kwon J, Ali B, et al: Role of hedgehog signaling in ovarian cancer. Clin Cancer Res 14: 7659-7666, 2008

24. Song LB, Li J, Liao WT, et al: The polycomb group protein Bmi-1 represses the tumor suppressor PTEN and induces epithelialmesenchymal transition in human nasopharyngeal epithelial cells. J Clin Invest 119: 3626-3636, 2009.

25. Song LB, Zeng MS, Liao WT, et al: Bmi-1 is a novel molecular marker of nasopharyngeal carcinoma progression and immortalizes primary human nasopharyngeal epithelial cells. Cancer Res 66: 6225-6232, 2006.

26. Kim JH, Yoon SY, Jeong SH, et al: Overexpression of Bmi-1 oncoprotein correlates with axillary lymph node metastases in invasive ductal breast cancer. Breast 13: 383-388, 2004.

27. Qin L, Zhang X, Zhang L, et al: Downregulation of BMI-1 enhances 5-fluorouracil-induced apoptosis in nasopharyngeal carcinoma cells. Biochem Biophys Res Commun 371: 531-535, 2008. 